The African 2k WG is also still developing. Mohammed Umer and David Nash presented an overview of available data for Eastern and Southern Africa, respectively, particularly highlighting the importance of understanding variations in rainfall and occurrence of extreme events (e.g., droughts). Once group participants are finalized, this WG will undertake a review and integration of high-resolution time series.

The Australasian $2 \mathrm{kWG}$ is moving forward following a workshop in 2005 and a resulting synthesis special issue. Joëlle Gergis presented a new temperature reconstruction for the region covering the last $\sim 500$ years, and highlighted new efforts to reconstruct regional temperature, precipitation and pressure using a suite of proxy records. This WG will now work towards extending the temporal and spatial coverage of time series, and reconstruction of the large-scale climate modes that drive climate in the region.

The Arctic 2k WG was launched in 2008 and has recently produced a compilation of temperature sensitive proxies from 23 sites around the Arctic. Darrell Kaufman highlighted this synthesis and demonstrated that temperatures in the 20th century reversed a millennial-scale cooling trend. Efforts are now being directed towards the development of additional proxy records, the inclusion of discontinuous timeseries and the reconstruction of the hydroclimatic variability of the region.

The Antarctic $2 \mathrm{k}$ effort is predominantly driven by the IPICS $2 k$ project. Representing this group, Eric Steig outlined a number of recent reconstructions and modeling results for various climatic parameters. A data synthesis paper focusing on century-scale variability during the last $1 \mathrm{ka}$ is currently in progress and several projects collecting 2 ka cores have recently begun.

Eugene Wahl gave a final presentation on the importance of contributing data to international databases, such as NOAA's World Data Center for Paleoclimatology. This is particularly pertinent for large-scale syntheses such as the $2 k$ Regional Network. Eugene also outlined the variety of database tools available to researchers, and prompted discussion on ways to improve database usability and efficiency.
The $2 \mathrm{k}$ Network will produce a synthesis book, including chapters on each region and an overall global synthesis chapter. Each regional chapter will discuss the climate of a number of key periods (e.g., Medieval Climate Anomaly, Little Ice Age, Maunder Minimum), with the global signal and driving dynamical changes summarized in the global chapter.

Further details are available from the PAGES website (http://www.pages-igbp. org/science/focus2themes).

\section{References}

Bown, F.and Rivera, A., 2007: Climate changes and recent glacier behaviour in the Chilean Lake District, Global and Planetary Change, 59: 79-86.

Lara, A., Villalba, R. and Urrutia, R., 2008: A 400-year tree-ring record of the Puelo River summer-fall streamflow in the Valdivian Rainforest eco-region, Chile, Climatic Change, 86: 331-356.

Masiokas, M.H., Rivera, A., Espizua, L.E., Villalba, R., Delgado, S. and Aravena, J.C., 2009: Glacier fluctuations in extratropical South America during the past 1000 years, Palaeogeography, Palaeoclimatology, Palaeoecology, 281: 242-268.

Villalba, R., Lara, A., Boninsegna, J.A., Urrutia, R. and Masiokas, M., 2006: Tree-ring temperature reconstructions in South America revisited. PAGES/CLIVAR Workshop. Past Millennia Climate Variability: Proxy based reconstructions, Modeling and Methodology - Synthesis and Outlook, Wengen, Switzerland.

For full references please consult:

www.pages-igbp.org/products/newsletters/ref2009_3.html

\title{
Young scientists meet to exchange science, network and learn about PAGES
}

\section{PAGES $1^{\text {st }}$ Young Scientists Meeting - Corvallis, USA, 6-7 July 2009}

\section{Pedro DiNezio', C. Cleroux², P. Applegate ${ }^{3}$ and P. Collins ${ }^{4}$ (YSM Participants)}

${ }^{1}$ Rosenstiel School of Marine and Atmospheric Science, University of Miami, USA; pdinezio@rsmas.miami.edu; 2 Lamont-Doherty Earth Observatory, Columbia University, Palisades, USA; ${ }^{3}$ Department of Geosciences, Pennsylvania State University, University Park, USA; ${ }^{4}$ École Polytechnique Fédérale de Lausanne, Switzerland

PAGES $1^{\text {st }}$ Young Scientists Meeting (YSM) offered a platform for scientific exchange, networking and career development for more than 90 young scientists from 21 countries. The meeting also provided these young scientists with information about PAGES and other international global change organizations. The scientific program was organized around PAGES four scientific Foci; 1) Climate Forcings; 2) Regional Climate Dynamics; 3) Global Earth System Dynamics; and 4) HumanClimate-Ecosystem Interactions. In addition, several presentations were dedicated to three of PAGES four Cross-Cutting Themes (CCTs); 1) Chronology; 2) Proxy Development, Calibration and Validation; 3) Modeling.

Participants included mostly students in the later stages of their PhD and early-career PhD graduates, selected by a competitive application process. The par- ticipants contributed to oral and poster sessions, and participated in informal breakout groups and discussions. Worldclass senior scientists also participated in the meeting with special lectures. The first day started with a talk on the relevance of paleoclimate research by Nicklas Pisias (Oregon State University). He raised important questions on aspects of past climates that are relevant for issues of global warming, such as climate sensitivity to external forcing, and mechanisms of climate change and feedbacks.

Nick Pisias' presentation set the stage for the young scientists, who followed with their own talks. The talks covered cuttingedge topics in paleoclimatology, such as evaluation of mechanisms and tipping points using data and models, reconstruction of past and recent climates, exploration of assumptions made in the development of proxies, attribution of past climate changes, and modeling of past climates. A flavor of the range of research reported is given by the following (purely subjective) selection of presentations.

For PAGES Focus 1, Catalina González (University of Bremen) showed a reconstruction of rapid sea-level change associated with Heinrich events, using pollen ecology from a marine core. Her analysis of the ecological response of intertidal tropical ecosystems in the Cariaco Basin provides evidence on the timing of sealevel changes during MIS 3 and their connection with Heinrich Events, supporting the idea that sea level fluctuated along with Antarctic climate. Alberto Reyes (University of Alberta) presented a record documenting the response of permafrost to last interglacial warming. This study suggests that carbon sequestered in near-surface permafrost is likely highly vulnerable to $21^{\text {st }}$-century warming, however deeper 
permafrost and its associated carbon reservoirs are probably more stable than previously thought. Jeremy Shakun (Oregon State University) presented new insights on the sensitivity of the climate system to $\mathrm{CO}_{2}$ forcing, based on an empirical orthogonal function analysis of all the available proxies of the last deglaciation. His analysis shows that proxies have a global temperature signal that is not correlated with ice sheet or insolation changes but is very well correlated with $\mathrm{CO}_{2}$ forcing. The relationship between $\mathrm{CO}_{2}$ forcing and global temperature suggests sensitivities to $\mathrm{CO}_{2}$ forcing in the upper range of the IPCC models. Akitomo Yamamoto (Hokkaido University) showed in a 1-D numerical model that massive releases of methane from the sea floor get dissolved in the ocean instead of reaching the atmosphere, suggesting that deep-sea methane releases are unable to cause massive changes in atmospheric composition.

Under PAGES Focus 2, Martin Tingley (Harvard University) presented a Bayesian model assimilating incomplete (in space and time) instrumental and proxy data sets. He used this model to reconstruct, with uncertainties, 600 years of surface temperatures for high northern latitudes, based on tree ring, ice core, and lake sediment core data, confirming the unprecedented nature of $20^{\text {th }}$-century warming (Fig. 1). For PAGES Focus 3, Jessica Tierney (Brown University) presented evidence of centennial-scale changes in rainfall amount in southwest Indonesia during the last two millennia, based on hydrogen isotopic ratios on terrestrial higher plant leaf waxes $\left(\delta D_{\text {leaf wax }}\right)$ in marine sediments. Under PAGES Focus 4, Megan Walsh (University of Oregon) discussed roles of natural environmental variability and human activity in shaping the fire and vegetation history of the Oregon region. Using charcoal and pollen analysis of lake sediments, she highlighted the variability in the drivers of fire history, from climate-driven vegetation shifts in some areas, to humaninfluenced regimes in others.

Several innovative studies were also presented for PAGES CCT 2. For example, Julie Ferguson (University of California Irvine) presented the first seasonal-resolution SST and seawater $\delta^{18} \mathrm{O}$ records for the LGM outside the tropics, showing winter cooling of up to $2^{\circ} \mathrm{C}$. Her results suggest that processes other than insolation controlled the seasonality of the SST response to glacial conditions. Branwen Williams (Ohio State University) presented a 100 -year record of $\delta^{15} \mathrm{~N}$ from a coral in the western Pacific, suggesting a shoaling of the equatorial thermocline during the

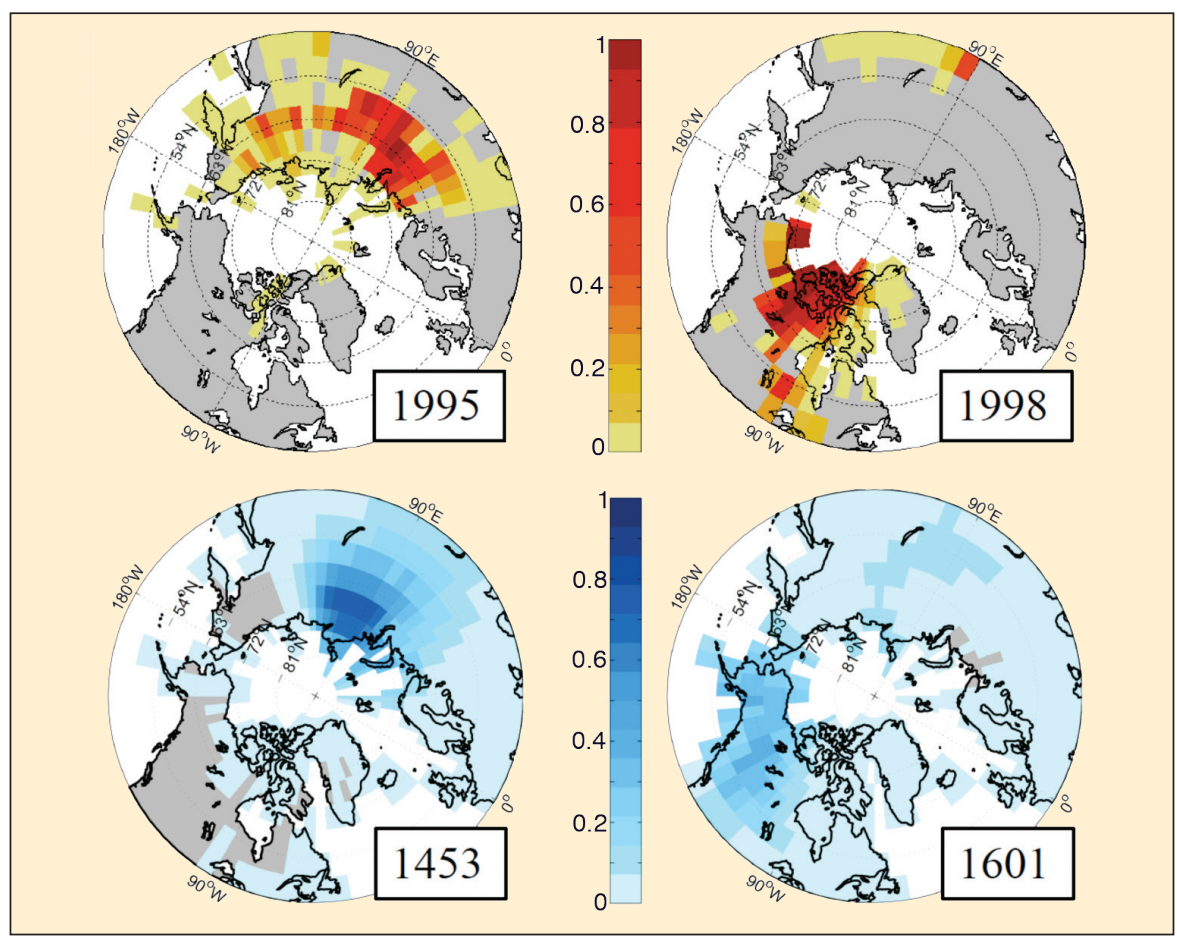

Figure 1: Warmest (top panel) and coldest (bottom panel) years in the Northern Hemisphere during the 1400-1999 period, estimated using a Bayesian methodology and proxy data (M. Tingley). $20^{\text {th }}$ century. The results from this study are very encouraging for understanding the ocean response to a weakening of the Walker circulation. Hopefully, more records of this type will help constrain our understanding of tropical climate change.

The afternoons were devoted to poster sessions. Modeling experiments over several time intervals that are useful for understanding the inner workings of the climate system, such as the LGM, the $8.2 \mathrm{ka}$ event, the Eemian, and the last 2 millennia, were presented in both the poster sessions (Jung-Eun Lee, University of Chicago; Sum- mer Rupper, Brigham Young University; Feng $\mathrm{He}$, University of Wisconsin-Madison) and talks of CCT3 (Andreas Born, University of Bergen; Steven Phipps, University of New South Wales). In addition to this, results from numerical simulations of stable isotopes showed that calibration equations based on modern climate do not necessarily apply to past climates. Analysis of proxies also sheds light on limitations of typical assumptions, for instance, Caroline Cleroux (Lamont-Doherty Earth Observatory) presented revealing evidence for changes in calcification depth of the

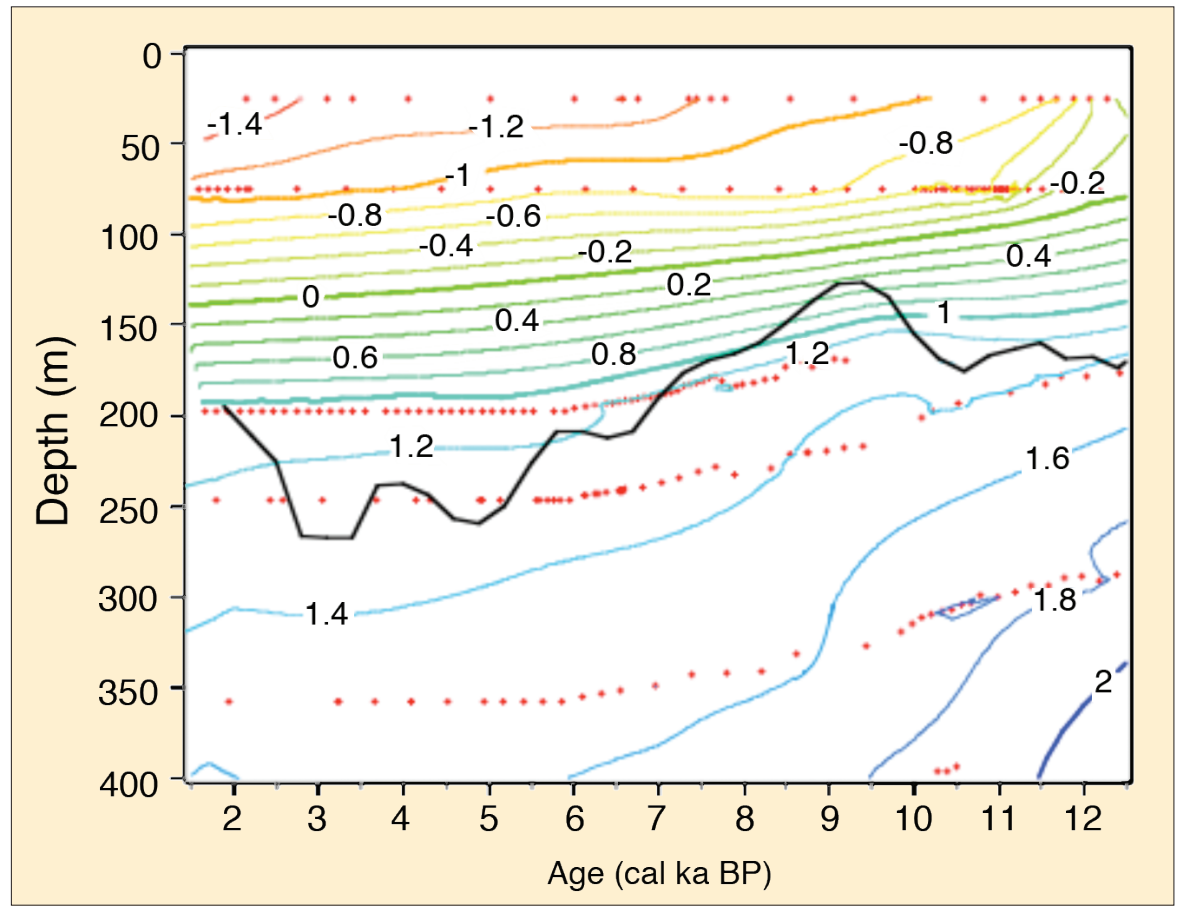

Figure 2: Calcification depth of the foraminifer Globorotalia truncatulinoides over the last $12.5 \mathrm{ka}$, calculated from $\delta^{18} \mathrm{O}$ reconstructions from planktonic and benthic foraminifera in the Florida Straits (figure reproduced with permission from Cleroux et al., 2009). 


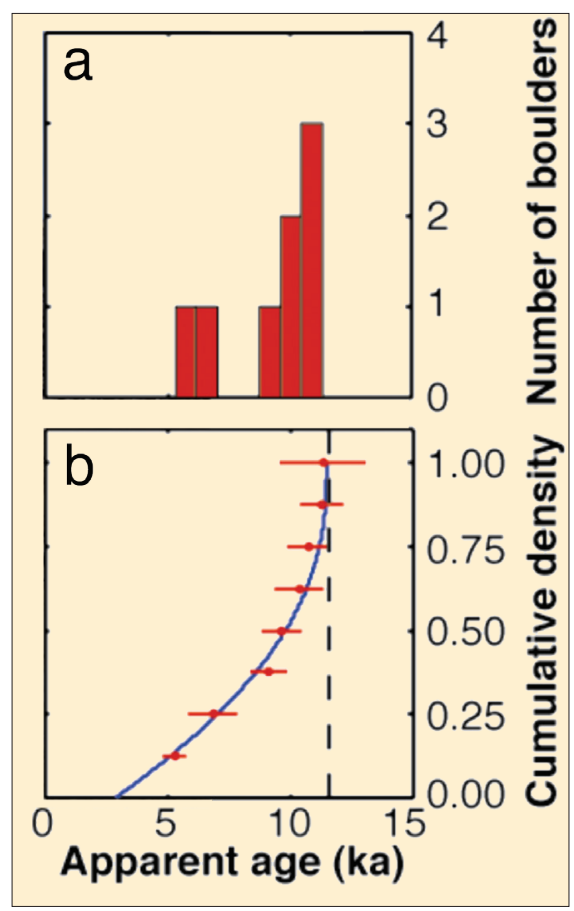

Figure 3: Cosmogenic nuclide concentrations in moraine boulders indicate the ages of the moraines but the apparent moraine ages yielded by different boulders on the same moraine often differ by thousands of years (a; Barrows et al., 2007). Geomorphic process modeling can help determine the age of a moraine from a highly scattered data set ( $\boldsymbol{b}$; Applegate et al., 2008).

foraminifer Globorotalia truncatulinoides between deglaciation and the Holocene. Her study emphasizes the need for better understanding of the ecology, life cycle, and controls on calcification depth for G. truncatulinoides and other planktonic foraminifera that are used to reconstruct the history of the thermocline and upper water column structure (Fig. 2). More assumptions typically used in the study of past climate were challenged in the poster session. Thomas Laepple (Alfred Wegener Institute) presented work that suggests that some climate records may be more strongly predicted by local insolation than insolation at high northern latitudes, after the seasonality of those climate records is taken into account. Pedro DiNezio (University of Miami) exposed the limitations of analogs, such as El Niño, to understanding tropical climate change. Patrick Applegate (Pennsylvania State University) presented numerical models of cosmogenic nuclide accumulation in boulders on glacial landforms. These models are able to explain the wide statistical distributions of cosmogenic exposure dates from certain moraines (Fig. 3). Pamela Collins (École Polytechnique Fédérale de Lausanne) used a coupled model of soil genesis and vegetation to examine pollen records from around the Mediterranean. Her work suggests that agricultural soil degradation may have caused an observed shift in pollen types that was previously attributed to a large-scale drying (Fig. 4).

On the final day, a number of presentations were given with the aim of providing information on key aspects of a researcher's career. Paul Filmer, PAGES Program Manager from the US National Science Foundation, provided background on research funding structures in the US. He anticipates opportunities in abrupt climate change and the hydrological cycle due to interest of the funding agencies in understanding tipping points and in having comprehensive hydrologic projections. For those interested in proxy development, Dr. Filmer indicated that the Paleo Perspectives in Climate Change (P2C2) program emphasizes producing climate data to test models, and gaining insight into mechanisms and rates of change. Dr. Prabir Dastidar from the Indian Ministry of Earth Sciences then addressed the Plenum with a brief account of a developing country's perspective on science funding.

This valuable information was complemented by the presentation of Alicia Newton (Associate Editor of Nature Geoscience), who provided insight into what high-impact journals expect. She emphasized that scientific results need to be clear conceptual advances in their fields to have a chance for publication in journals like Nature or Science. In addition to this, she

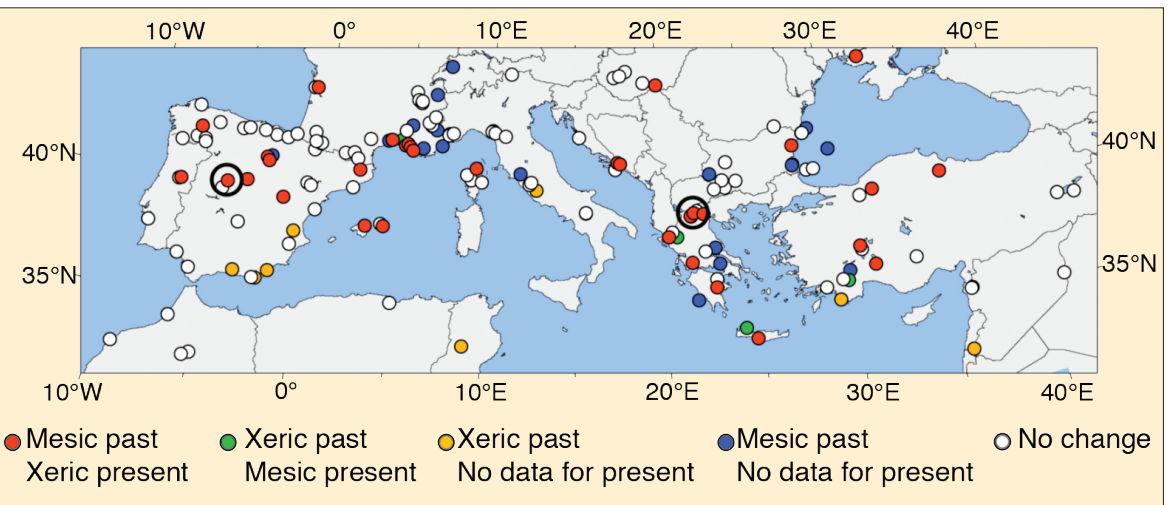

Figure 4: Map of the analyzed pollen-based biomizations for $6 \mathrm{ka}$ and present day from sites throughout the Mediterranean; red circles indicate those sites that currently support xeric (adapted to dry habitats) vegetation but that contained mesic (requiring moderate water) biomes at $6 \mathrm{ka}$ (P. Collins). reminded young scientists that aside from data and conclusions, clarity is very important. Thorsten Kiefer, from the EGU journal Climate of the Past, then introduced the relatively novel concept of open-access publishing and public, transparent peerreview.

David Anderson from NOAA's Paleoclimatology Program discussed issues of data management and explained that NOAA is interested in paleoclimatology to improve our understanding of decadal variability, extend the instrumental record into the past, and understand abrupt climate change.

To conclude, Gavin Schmidt from NASA/GISS presented important issues that arise when science is communicated to non-scientists. He recommended avoiding scientific discussions where scientific method is not followed. Additionally, he reminded us that scientists have a responsibility to avoid sensationalism and over-extrapolated conclusions from their work. He advised to state the implications of new work carefully, without overselling the results, and explicitly stating what the results do not mean when press releases are made.

The YSM successfully bridged the gap between summer schools and conferences by providing a relaxing environment to learn from colleagues from other fields. Simultaneously, it facilitated networking between emerging young scientists and introduced them to organizational aspects of science, such as funding, publishing, and communication of results. The concept behind this meeting worked efficiently to support the young scientists on their initial steps toward advancing the field of paleoclimatology.

\section{Note}

For more information on the figures here, and the talks and posters presented at the YSM please visit http://www.pages-osm.org/ysm/.

\section{References}

Applegate, P.., Lowell, T.V. and Alley, R.B., 2008: Comment on "Absence of Cooling in New Zealand during the Younger Dryas Chronozone", Science, 320: 746.

Barrows, T.T., Lehman, S.J., Fifield, L.K. and de Deckker, P. 2007: Absence of Cooling in New Zealand during the Younger Dryas Chronozone, Science, 318: 86-89.

Cleroux, C., Lynch-Stieglitz, J., Schmidt, M.W., Cortijo, E. and Duplessy, J.-C., 2009: Evidence for calcification depth change of $G$. truncatulinoides between Deglaciation and Holocene in the western Atlantic Ocean, Marine Micropaleontology, DOI: 10.1016/j.marmicro.2009.07.001 